\title{
A Preliminary Evaluation of Symbiotic N Fixation in Mungbean
}

\author{
Charles Salley ${ }^{1} \&$ Harbans L. Bhardwaj ${ }^{1}$ \\ ${ }^{1}$ Agricultural Research Station, Virginia State University, Petersburg, Virginia, USA \\ Correspondence: Harbans L. Bhardwaj, Agricultural Research Station, Virginia State University, Petersburg, \\ Virginia 23806, USA. Tel: 1-804-524-6723. Fax: 1-804-524-5950. E-mail: hbhardwaj@vsu.edu
}

Received: May 17, $2018 \quad$ Accepted: June 27, $2018 \quad$ Online Published: August 15, 2018
doi:10.5539/jas.v10n9p1
URL: https://doi.org/10.5539/jas.v10n9p1

The research is financed by US Department of Agriculture-Evans-Allen Program.

\begin{abstract}
We are interested in developing mungbean [(Vigna radiata $($ L.) R. Wilczek] as a short duration summer crop to be produced in rotation with winter wheat due to its' increasing popularity and potential for Symbiotic N Fixation (SNF). However, scarcity of mungbean SNF information is limiting to support its use as an N-fixing crop. We conducted a greenhouse study with ten mungbean genotypes and twelve Bradyrhizobium strains. The objective was to study nodule traits (number and size) and chlorophyll concentration in leaves using Minolta SPAD meter using a CRD design with six replications. Eight to ten seeds of each of the 120 combinations were planted in vermiculite and inoculated with the bacterial strains. Upon germination, plants were thinned to six plants per pot. The data were recorded on approximately 40-day old plants. Results indicated that variation for nodule traits was not significant. However, significant effects of bradyrhizobial strains and mungbean genotypes on SPAD readings were observed. Results indicated existence of specificity between mungbean genotypes and bradyrhizobial strains, as indicated by significant interaction for SPAD values. We identified three bradyrhizobial strains (Strain-11 isolated from partridge pea, Strain-12 isolated from Baptisia sp., and Strain-3-CB 756, wide range type strain from Australia) to be highly efficient. Three mungbean genotypes (MB-80, TexSprout, and MB-84) were identified to be best for SNF. The results provide basic information to support future detailed SNF research in mungbean.
\end{abstract}

Keywords: Vigna radiata, Bradyrhizobium strains, SPAD readings, sustainable food production

\section{Introduction}

The current study addresses two issues: crop diversification and Symbiotic N Fixation (SNF) to reduce/eliminate $\mathrm{N}$ fertilizer use to support low-cost and sustainable food production. Need for crop diversification and development of crop varieties for sustainable food production are recognized as important factors for production of adequate and nutritious food for growing human population on a world-wide basis on limited soil resources. This is especially true of US agriculture which depends upon a limited number of crops. New crops have been important to the American agriculture. Most crops, currently, grown in the United States, were imports from different parts of the world. Mungbean, a member of the Fabaceae family (also known as the Leguminosae family) along with the common pea, chickpea, soybean, alfalfa, and other crops, has been identified as a potential crop for Virginia and the mid-Atlantic region of United States of America (Pal et al., 2011).

Recent research has indicated that mungbean can be easily produced in Virginia, the mid-Atlantic region and the southern USA (Bhardwaj \& Hamama, 2015). This research using two cultivars (Berken and TexSprout), two planting dates (early and late July), and two row spacings $(37.5$ and $75 \mathrm{~cm}$ ) indicated that cultivar and planting date effects on seed yield were not significant, however, narrow row spacing resulted in significant higher seed yield and concentration of protein over the wider row spacing (1.76 vs. $0.86 \mathrm{Mg} \cdot \mathrm{ha}^{-1}$ yield and $24.9 \%$ vs. $23.7 \%$ protein). Early planting resulted in lower sugar and oil concentrations over late planting (4.4\% vs. $5.5 \%$ sugar and $1.24 \%$ vs. $1.99 \%$ oil). Average mungbean values for seed yield, seed size, and concentrations of protein,

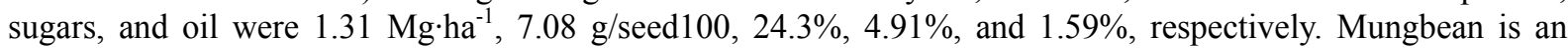
important crop in the United States-approximately 28, 30, and 30 million pounds were imported into USA during 2012, 2013, and 2014, respectively (ERS, 2018). 
$\mathrm{N}$ is an essential for plant growth and productivity. It is an essential constituent of plant protoplasm. Even though about $80 \%$ of earth's atmosphere is $\mathrm{N}$ gas, plants can't use $\mathrm{N}$ in its' inert form and must be converted to its' usable form like ammonia before it can be used by plants. The use of inorganic fertilizers, especially nitrogen, has been an enigma for modern agriculture: on one hand, their use has been linked to environmental pollution, while on the other hand they have contributed to yield increases (Drinkwater et al., 1998). In comparison with conventional, high-intensity agricultural methods, organic alternatives can improve soil fertility and have fewer detrimental effects on the environment. The most effective system of biological $\mathrm{N}$ fixation involves the symbiotic relationship between bacteria of genera Rhizobium and Bradyrhizobium and plants of the family Leguminosae (Poehlman, 1991). N-fixing bacteria that nodulate mungbean are taxonomically classified as Bradyrhizobium sp. (Poehlman, 1991). These bacteria may be further differentiated into genetic entities or strains that differ in host range infectivity. Previous research with white lupin (Lupinus albus and Tepary bean Phaseolus acutifolius) has indicated existence of bacterial specificity towards host legume plants (Robinson et al., 2000; Mapp et al., 2016; Mohrmann et al., 2017; Staples et al., 2017). However, similar information related to SNF in mungbean is scarce. Therefore, the objective of this study was to characterize SNF in mungbean.

\section{Materials and Methods}

We conducted an experiment in a greenhouse located on Randolph Farm of Virginia State University $\left(37^{\circ} 15^{\prime} \mathrm{N}\right.$ and $077^{\circ} 30.8^{\prime} \mathrm{W}$ ) to characterize SNF in mungbean by evaluating six replications of each combination of ten mungbean genotypes and twelve bradyrhizobial strains. The mungbean genotypes were: MB-19, MB-80, MB-84, MB-123, MB-133, TexSprout, Berken, OK-2000, Lincoln, and OK-12. The twelve bradyrhizobial strains were:

Strain-1: Isolated from Mungbean, Missouri, 2003;

Strain-2: Isolated from cowpea, Missouri, 2005;

Strain-3: CB 756 wide range type strain from Australia;

Strain-4: NGR 234 wide range strain- isolated from lablab in Papua New Guinea;

Strain-5: Isolated from partridge pea, Indiana, 2014;

Strain-6: Isolated from Desmodium sp., Missouri 2005;

Strain-7: TAL 1000-from Niftal collection, Hawaii-used for peanut;

Srain-8: Isolated from lablab, Indiana, 2005;

Strain-9: Isolated from lablab, Indiana, 2008;

Strain-10: Isolated from Desmodium sp., Indiana, 2008;

Strain-11: Isolated from partridge pea, Indiana, 2010;

Strain-12: Isolated from Baptisia sp., Indiana, 2008.

In this experiment, $30 \mathrm{~cm}$ tall plastic pots (approximate volume of four liters) were filled with moistened coarse sterilized vermiculite. Eight to ten seeds of each genotype were planted in each pot approximately $3 \mathrm{~cm}$ deep. Peat-based powdery liquid inoculant was released on the seed. This was done repeatedly for every pot using a new pipette. Care was taken to avoid cross contamination among rhizobial strains. A total of 120 combinations were used in a Completely Randomized Design. After inoculation, the seeds were immediately covered with planting material and then watered liberally. Upon germination, plants in each pot were thinned to six per pot. Each plant was considered a replication. The experiment was conducted during 2017.

Chlorophyll count of each plant was recorded from 4-5 leaves per intact plant when plants were approximately 40 day old using a Minolta SPAD-502. Approximately 40-day old plants were gently removed from the pots and washed with a gentle water stream of water and nodule size and nodule number scores were recorded each using the following scale: Nodule size scores $(1=$ Small sized nodules similar in size to mustard seed; $2=$ Medium sized nodules and $3=$ Large sized nodules greater in size than soybean seed $)$, Nodule number scores $(1=$ Less than 5 nodules; 2 = More than 10 nodules and $3=$ More than 20 nodules). All data were analyzed using SAS Version 9.4 to characterize significance of replications, genotypes, bacterial strains, and the interaction between genotypes and bacterial strains. Duncan's Multiple Range Test (5 percent level of significance) was used for mean separation (SAS, 2012).

\section{Results and Discussion}

The experiment was successfully completed. Analysis of Variance indicated lack of significant effects of mungbean genotypes and Bradyrhizobial strains on nodule number and nodule size. However, effects of 
mungbean genotypes and Bradyrhizobial strains on SPAD readings were highly significant (Table 1). The interaction between genotypes and strains was also highly significant. However, magnitude of mean squares due to mungbean genotypes and Bradyrhizobium strains were about 3 and 6 times greater in magnitude that that due to interaction. Therefore, we decided to present results based on main effects i.e. mungbean genotypes and Bradyrhizobium strains.

Table 1. Analysis of variance (Mean Squares) for SPAD readings recorded on 40-day plants of ten mungbean genotypes inoculated with twelve Bradyrhizobial strains and grown in a greenhouse during 2017

\begin{tabular}{lll}
\hline Source & Mean squares & Probability \\
\hline Replications & 17.5 & 0.1806 \\
Genotypes (G) & 128.5 & $<0.0001$ \\
Strains (S) & 298.0 & $<0.0001$ \\
G $\times$ S & 46.9 & $<0.0001$ \\
Error & 74.0 & - \\
\hline
\end{tabular}

Based on overall means, the SPAD values for ten mungbean genotypes ranged from 31.1 to 34.9 (Table 2) and those for twelve Bradyrhizobium strains varied from 29.1 to 36.1 (Table 3). The coefficient of variation in this study was $10.4 \%$ whereas the $\mathrm{R}^{2}$ was $59.3 \%$. This $\mathrm{R}^{2}$ values indicate that the conduct of this greenhouse was satisfactory even though an improvement might be desirable. Based on these preliminary results, we identified three bradyrhizobial strains (Strain-11 isolated from partridge pea, Strain-12 isolated from Baptisia sp., and Strain-3-CB 756, wide range type strain from Australia) were identified to be highly efficient for SNF and bradyrhizobial strains (Strain-4-NGR 234 wide range strain isolated from lablab in Papua New Guinea, Srain-8 isolated from lablab, and Strain-6 isolated from Desmodium sp.) were observed to be least efficient for SNF. On the other hand, mungbean genotypes MB-80, TexSprout, and MB-84 were observed to be best for SNF whereas mungbean genotypes Berken, OK-2000, and MB-19 were observed to be least efficient for SNF.

Table 2. SPAD values from 40-day old ten mungbean genotypes inoculated with twelve Bradyrhizobial strains and grown in a greenhouse during 2017

\begin{tabular}{lll}
\hline No. & Genotype & SPAD value \\
\hline 1 & MB-19 & $31.4 \mathrm{f}^{*}$ \\
2 & MB-80 & $34.9 \mathrm{a}$ \\
3 & MB-84 & $33.9 \mathrm{abc}$ \\
4 & MB-123 & $32.7 \mathrm{cde}$ \\
5 & MB-133 & $33.2 \mathrm{bcd}$ \\
6 & TexSprout & $34.2 \mathrm{ab}$ \\
7 & Berken & $31.1 \mathrm{f}$ \\
8 & OK-2000 & $31.2 \mathrm{f}$ \\
9 & Lincoln & $32.3 \mathrm{edf}$ \\
10 & OK-12 & $31.9 \mathrm{ef}$ \\
\hline
\end{tabular}

Note. * Means followed by similar letters were not different according to Duncan's Multiple Range Test at 5\% level of significance. Means over twelve Bradyrhizobial strains. 
Table 3. SPAD values from twelve Bradyrhizobial strains used to inoculate ten mungbean genotypes and grown in a greenhouse during 2017

\begin{tabular}{lll}
\hline No. & Strain & SPAD value \\
\hline 1. & Strain-1 & $33.6 \mathrm{~cd}^{*}$ \\
2. & Strain-2 & $32.1 \mathrm{e}$ \\
3. & Strain-3 & $34.8 \mathrm{abc}$ \\
4. & Strain-4 & $29.1 \mathrm{f}$ \\
5. & Strain-5 & $32.5 \mathrm{de}$ \\
6. & Strain-6 & $31.2 \mathrm{e}$ \\
7. & Strain-7 & $31.7 \mathrm{e}$ \\
8. & Strain-8 & $29.4 \mathrm{f}$ \\
9. & Strain-9 & $34.5 \mathrm{~cd}$ \\
10. & Strain-10 & $31.6 \mathrm{e}$ \\
11. & Strain-11 & $36.1 \mathrm{a}$ \\
12. & Strain-12 & $35.8 \mathrm{ab}$ \\
\hline
\end{tabular}

Note. * Means followed by similar letters were not different according to Duncan's Multiple Range Test at 5\% level of significance. Means over ten mungbean genotypes.

We were able to identify only a few SNF studies related to mungbean. A search of AGRICOLA database for Vigna radiata returned 1865 results out of which 59 dealt with nitrogen fixation and 11 dealt with SNF. Out of these 11 citations, two dealt with presence of nematodes on nodulation, one dealt with uptake activity of positive hydrogen related to SNF of mutants, one dealt with shoot signal, one dealt with nodule chemistry following cement kiln exhaust, one dealt with need for a specific gene for SNF, and the remaining five mentioned Bradyrhizobium strains and SNF in mungbean. Mathu et al. (2012) observed that Bradyrhizobium collected from different soils in Kenya had different SNF efficiencies implying a differential efficacies of strains and suggested a preference for indigenous strains. Rai and Prasad (1984) studied growth of one Rhizobium strain for growth under acid, saline, and alkaline media and reported that soil stress did not affect rhizobial growth. Risal et al. (2012) used a local mungbean cultivar to trap bradyrhizobia from different regions of Nepal and based on inoculation tests reported that expression of different symbiotic genes resulted in different degrees of symbiotic functions implying differential efficacies of bradyrhizobial strains. Choudhary et al. (2018) isolated nodule bacteria from Senegalia senegal tree and reported that these strains could nodule Vachellia species but not Vigna radiata. Similarly, Hafeez et al. (1995) reported that fast growing rhizobia from Macroptilium atropurpureum could nodulate Glycine max, Leucaena leucocephala but not Vigna radiata. A relevant study was reported by Christopher et al. (2018). They tested the hypothesis that wild bradyrhizobia (Bradyrhizobium spp.) were as effective as commercial inoculum for mungbean (Vigna radiata) in Australia by sampling diversity of bradyrhizobial strains from two field sites and from plants grown in inoculated or uninoculated soils and comparing two wild Bradyrhizobium with the commercial strain for their ability for SNF. They reported that some wild bradyrhozobia may be as effective as commercial inoculum for mungbean and black gram, potentially abrogating the need for artificial inoculation, and perhaps offering new options for the future development of better adapted commercial inoculum.

We conclude that specificity exists between mungbean genotypes and Bradyrhizobium strains. However, these results are only from one study and we suggest additional research to characterize SNF in greater detail. Our results, however, provide a general starting point for further SNF studies with mungbean. The presence of this type of specificity is well documented in SNF studies (Mapp et al., 2016; Mohrmann et al., 2017; Staples et al., 2017; Robinson et al., 2000).

\section{Acknowledgements}

Authors are thankful to Virginia State University and US Department of Agriculture for supporting this research with financial and physical resources.

\section{References}

Bhardwaj, H. L., \& Hamama, A. A. (2015). Cultivar, Planting Date, and Row Spacing Effects on Mungbean Performance in Virginia. HortScience, 50(9), 1309-1311. https://doi.org/10.5539/jas.v8n10p26 
Choudhary, S., Takb, N., \& Gehlotb, H. S. (2018). Phylogeny and Genetic Diversity Assessment of Ensifer Strains Nodulating Senegalia (Acacia) senegal (L.) Britton. in Arid Regions of Western Rajasthan, India. Microbiology, 87(1), 127-142. https://doi.org/10.1134/S0026261718010058

Christopher, M., Macdonald, B., Yeates, S., Ziegler, D., \& Seymour, N. (2018). Wild bradyrhizobia that occur in the Burdekin region of Queensland are as effective as commercial inoculum for mungbean [Vigna radiata (L.)] and black gram [Vigna mungo (L.)] in fixing nitrogen and dry matter production. Applied Soil Ecology, 124, 88-94. https://doi.org/10.1016/j.apsoil.2017.11.005

Drinkwater, L. E., Wagoner, P., \& Sarraantonio, M. (1998). Legume-based cropping systems have reduced carbon and nitrogen losses. Nature, 396, 262-265. https://doi.org/10.1038/24376

ERS. (2018). Vegetables and Pulses Data. USDA-Economic Research Service. Retrieved March 3, 2017, from http://www.ers.usda.gov/data-products/vegetables-and-pulses-data/by-commodity.aspx

Hafeez, F. Y., Asad, S., Ahmad, T., \& Malik, K. A. (1995). Host specificity and characterization of fast-growing rhizobia from Macroptilium atropurpureum cv. Siratro in Pakistan. Soil Biology and Biochemistry, 27, 729-733. https://doi.org/10.1016/0038-0717(95)98657-A

Mapp, C. D., Knight-Mason, R., \& Bhardwaj, H. L. (2016). Symbiotic N Fixation: Nodulation of Tepary Bean (Phaseolus acutifolius A. Gray). Journal of Plant Science \& Research, 3(1), 1-6.

Mathu, S., Herrmann, L., Pypers, P., Matiru, V., Mwirichia, R., \& Leseur, D. (2012). Potential of indigenous bradyrhizobial versus commercial inoculants to improve cowpea (Vigna unguiculata L. Walp.) and green gram (Vigna radiata L. Wilczek) yields in Kenya. Soil Science and Plant Nutrition, 58, 750-763. https://doi.org/10.1080/00380768.2012.741041

Mohrmann, M. D., Bhardwaj, H. L., Shen, H., \& Knight-Mason, R. (2017). Symbiotic N Fixation: Plant-Microbe Interaction between Tepary Bean and Bradyrhizobium Strains. Journal of Plant Science \& Research, 4(1), 1-4.

Pal, D., Mishra, P., Sachan, N., \& Ghosh, A. K. (2011). Biological activities and medicinal properties of Cajanus cajan (L.) Millsp. Journal of Advanced Pharmaceutical Technology and Research, 2(4), 207-214. https://doi.org/10.4103/2231-4040.90874

Poehlman, J. M. (1991). The Mungbean. Westview Press, Colorado, USA.

Rai, R., \& Prasad, V. (1984). Studies on growth and symbiotic nitrogen fixation of Rhizobium of Vigna radiata under stress conditions. The Journal of Agricultural Science, 102(2), 399-404. https://doi.org/10.1017/ S0021859600042738

Risal, C. P., Djedidi, S., Dhakal, D., Ohkama-Ohtsu, N., Sekimoto, H., \& Yokoyama, T. (2012). Phylogenetic diversity and symbiotic functioning in mungbean (Vigna radiata L. Wilczek) bradyrhizobial from contrast agro-ecological regions of Nepal. Systematic and Applied Microbiology, 35, 45-53. https://doi.org/10.1016/ j.syapm.2011.06.004

Robinson, K. O., Beyene, D. A., Berkum, P. van, Knight-Mason, R., \& Bhardwaj, H. L. (2000). Variability in plant microbe interaction between Lupinus lines and Bradyrhizobium strains. Plant Science, 159, 257-264. https://doi.org/10.1016/S0168-9452(00)00345-9

SAS. (2012). SAS for Windows. SAS Institute Inc., Cary, NC, USA.

Staples, K. D., Hamama, A. A., Knight-Mason, R., \& Bhardwaj, H. L. (2017). Alkaloids in White Lupin and Their Effects on Symbiotic N Fixation. Journal of Agricultural Science, 9(6), 13-21. https://oi.org/ $10.5539 /$ jas.v9n6p13

\section{Copyrights}

Copyright for this article is retained by the author (s), with first publication rights granted to the journal.

This is an open-access article distributed under the terms and conditions of the Creative Commons Attribution license (http://creativecommons.org/licenses/by/4.0/). 